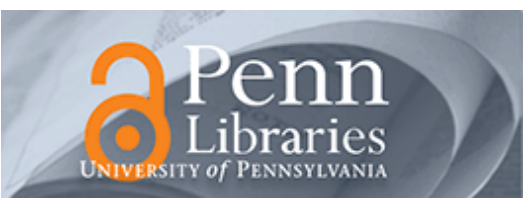

University of Pennsylvania

ScholarlyCommons

2-21-2012

\title{
Environmental Chamber for in Situ Dynamic Control of Temperature and Relative Humidity During X-Ray Scattering
}

\author{
David Salas-de la Cruz \\ University of Pennsylvania \\ Jeffrey G. Denis \\ University of Pennsylvania \\ Matthew D. Griffith \\ Gore Electrochemical Technologies \\ Daniel R. King \\ University of Pennsylvania \\ Paul A. Heiney \\ University of Pennsylvania, heiney@sas.upenn.edu \\ Follow this and additional works at: https://repository.upenn.edu/physics_papers \\ e next page for additional authors \\ Part of the Physics Commons
}

\section{Recommended Citation}

Salas-de la Cruz, D., Denis, J. G., Griffith, M. D., King, D. R., Heiney, P. A., \& Winey, K. I. (2012). Environmental Chamber for in Situ Dynamic Control of Temperature and Relative Humidity During X-Ray Scattering.

Retrieved from https://repository.upenn.edu/physics_papers/229

Salas-de la Cruz, D., Denis, J. G., Griffith, M. D., King, D. R., Heiney, P. A., \& Winey, K. I. (2012). Environmental chamber for in situ dynamic control of temperature and relative humidity during x-ray scattering. Review of Scientific Instruments, 83(2), 025112. doi: 10.1063/1.3685753

(C) 2012 American Institute of Physics. This article may be downloaded for personal use only. Any other use requires prior permission of the author and the American Institute of Physics. The following article appeared in Rev. Sci. Instrum. 83, 025112 (2012) and may be found at http://link.aip.org/link/?rsi/83/025112

This paper is posted at ScholarlyCommons. https://repository.upenn.edu/physics_papers/229

For more information, please contact repository@pobox.upenn.edu. 


\title{
Environmental Chamber for in Situ Dynamic Control of Temperature and Relative Humidity During X-Ray Scattering
}

\begin{abstract}
We have designed, constructed, and evaluated an environmental chamber that has in situ dynamic control of temperature $\left(25\right.$ to $90{ }^{\circ} \mathrm{C}$ ) and relative humidity ( $0 \%$ to $\left.95 \%\right)$. The compact specimen chamber is designed for $x$-ray scattering in transmission with an escape angle of $2 \theta= \pm 30^{\circ}$. The specimen chamber is compatible with a completely evacuated system such as the Rigaku PSAXS system, in which the specimen chamber is placed inside a larger evacuated chamber (flight path). It is also compatible with $\mathrm{x}$ ray systems consisting of evacuated flight tubes separated by small air gaps for sample placement. When attached to a linear motor (vertical displacement), the environmental chamber can access multiple sample positions. The temperature and relative humidity inside the specimen chamber are controlled by passing a mixture of dry and saturated gas through the chamber and by heating the chamber walls. Alternatively, the chamber can be used to control the gaseous environment without humidity. To illustrate the value of this apparatus, we have probed morphology transformations in Nafion ${ }^{\circledR}$ membranes and a polymerized ionic liquid as a function of relative humidity in nitrogen.
\end{abstract}

\section{Disciplines}

Physical Sciences and Mathematics | Physics

\section{Comments}

Salas-de la Cruz, D., Denis, J. G., Griffith, M. D., King, D. R., Heiney, P. A., \& Winey, K. I. (2012). Environmental chamber for in situ dynamic control of temperature and relative humidity during $\mathrm{x}$-ray scattering. Review of Scientific Instruments, 83(2), 025112. doi: 10.1063/1.3685753

(C) 2012 American Institute of Physics. This article may be downloaded for personal use only. Any other use requires prior permission of the author and the American Institute of Physics. The following article appeared in Rev. Sci. Instrum. 83, 025112 (2012) and may be found at http://link.aip.org/link/?rsi/83/ 025112

Author(s)

David Salas-de la Cruz, Jeffrey G. Denis, Matthew D. Griffith, Daniel R. King, Paul A. Heiney, and Karen I. Winey 


\title{
Environmental chamber for in situ dynamic control of temperature and relative humidity during $x$-ray scattering
}

\author{
David Salas-de la Cruz, ${ }^{1}$ Jeffrey G. Denis, ${ }^{2}$ Matthew D. Griffith, ${ }^{3}$ Daniel R. King, ${ }^{2}$ \\ Paul A. Heiney, ${ }^{4}$ and Karen I. Winey ${ }^{1,2}$ \\ ${ }^{1}$ Chemical and Biomolecular Engineering Department, University of Pennsylvania, Philadelphia, \\ Pennsylvania 19104, USA \\ ${ }^{2}$ Materials Science and Engineering Department, University of Pennsylvania, Philadelphia, \\ Pennsylvania 19104, USA \\ ${ }^{3}$ Gore Electrochemical Technologies, 201 Airport Road, P. O. Box 1488, Elkton, Maryland 21922-1488, USA \\ ${ }^{4}$ Department of Physics and Astronomy, University of Pennsylvania, Philadelphia, Pennsylvania 19104, USA
}

(Received 30 September 2011; accepted 31 January 2012; published online 21 February 2012)

\begin{abstract}
We have designed, constructed, and evaluated an environmental chamber that has in situ dynamic control of temperature $\left(25\right.$ to $\left.90{ }^{\circ} \mathrm{C}\right)$ and relative humidity $(0 \%$ to $95 \%)$. The compact specimen chamber is designed for $\mathrm{x}$-ray scattering in transmission with an escape angle of $2 \theta= \pm 30^{\circ}$. The specimen chamber is compatible with a completely evacuated system such as the Rigaku PSAXS system, in which the specimen chamber is placed inside a larger evacuated chamber (flight path). It is also compatible with x-ray systems consisting of evacuated flight tubes separated by small air gaps for sample placement. When attached to a linear motor (vertical displacement), the environmental chamber can access multiple sample positions. The temperature and relative humidity inside the specimen chamber are controlled by passing a mixture of dry and saturated gas through the chamber and by heating the chamber walls. Alternatively, the chamber can be used to control the gaseous environment without humidity. To illustrate the value of this apparatus, we have probed morphology transformations in Nafion ${ }^{\circledR}$ membranes and a polymerized ionic liquid as a function of relative humidity in nitrogen. (C) 2012 American Institute of Physics. [http://dx.doi.org/10.1063/1.3685753]
\end{abstract}

\section{INTRODUCTION}

The environmental chamber described in this paper for transmission $\mathrm{x}$-ray scattering can be used to characterize materials that have scientifically interesting structural transformations as a function of temperature, relative humidity, non-corrosive gases, or mixtures of gases. This device allows materials to be studied under conditions that mimic various applications and scenarios including: membranes for fuel cells, ${ }^{1-5}$ membranes for actuators, ${ }^{6,7}$ materials in corrosive environments (simulated aging), ${ }^{8,9}$ naturally occurring materials, ${ }^{10}$ biomimetic materials, ${ }^{11}$ and catalyst materials affectivity. ${ }^{12}$ For instance, Smith et al. ${ }^{13}$ demonstrated a correlation between chemical potential of water and morphology by performing $\mathrm{x}$-ray scattering studies of oriented dimyristoyphosphatidylcholine-water lamellar films using an in situ triple axis $\mathrm{x}$-ray spectrometer at a controlled temperature and relative humidity. Comparatively, Halim and Scherer ${ }^{14}$ were able to correlate and understand the electrochemical and morphological properties of Nafion ${ }^{\circledR}$ film as a function of relative humidity using small- and wide-angle $\mathrm{x}$-ray scattering under different humidities. Finally, Bang et $a l .{ }^{15}$ investigated the effect of humidity on the ordering of poly(ethylene oxide)-based copolymer thin films where it was shown that by annealing a poly(ethylene oxide- $b$ methylmethacrylate- $b$-styrene)triblock copolymer under high humidity the lamellar morphology in the bulk developed a hexagonal array of poly(ethylene oxide) microdomains.

Environmental chambers have been previously designed for a range of specific x-ray scattering or neutron scattering experiments. For example, Kim et al. ${ }^{16}$ designed an in situ vapor sorption apparatus, for small-angle neutron scattering, with a temperature range from 0 to $150{ }^{\circ} \mathrm{C}$ and a relative humidity range from $0 \%$ to $90 \%$. The $\% \mathrm{RH}$ is controlled by measuring the absolute pressure and the apparatus has the capability to inject a pore-masking liquid in the sample cell. In contrast, Smith et al. ${ }^{13,17}$ developed a humidity oven for neutron and synchrotron $\mathrm{x}$-ray scattering which has a temperature range from 0 to $80^{\circ} \mathrm{C}$ and a relative humidity range from $0 \%$ to $100 \%$ RH. Katsaras and Watson ${ }^{18}$ assembled a sample cell capable of attaining $100 \% \mathrm{RH}$ for a synchrotron x-ray diffraction system. The sample cell has a temperature range from 5 to $80^{\circ} \mathrm{C}$ and the humidity is controlled by a porous membrane located near the sample. Giahi et al. ${ }^{19}$ developed an alternative design using two humidity chambers where the humidity was controlled by an internal water/salt mixture. The chambers allow experiments in aqueous solutions and are fully compatible with $\mathrm{x}$-ray scattering, $\mathrm{x}$-ray non-specular (diffuse) scattering and grazing incidence scattering.

We report a new design for an environmental chamber (EC) that controls temperature and relative humidity during transmission scattering. Key features of this new design include a large escape angle, compatibility with an evacuated system such as the Rigaku PSAXS system, a sample mount for multiple specimens, dynamic control of temperature and relative humidity, and integrated computer control for both chamber conditions and data collection. The EC can also be used to control the gaseous environment during scattering experiments to probe chemical reactions. This in situ apparatus will enable advances in the fundamental understanding of the 
TABLE I. Environmental chamber (EC) descriptions and capabilities.

\begin{tabular}{lc}
\hline \hline Parameter & Description \\
\hline Type of radiation & X-ray \\
Geometry & Transmission \\
Escape angle, $2 \theta$ (horizontally) & $\pm 30^{\circ}$ \\
Temperature range & $25-90^{\circ} \mathrm{C}$ \\
Temperature precision & $0.05-0.5^{\circ} \mathrm{C}$ \\
Temperature gradient across sample & $<1{ }^{\circ} \mathrm{C}$ \\
Humidity range & $0 \%-95 \%$ \\
Humidity precision & $1.5 \% \mathrm{RH}$ at $30^{\circ} \mathrm{C}$ \\
& $3 \% \mathrm{RH}$ at $80^{\circ} \mathrm{C}$ \\
\hline
\end{tabular}

relationship between morphology, temperature, relative humidity, and gaseous environments. To illustrate the value of this apparatus, transient morphologies in Nafion ${ }^{\circledR}$ membranes (E. I. DuPont de Nemours and Company) and imidazoliumbased polymerized ionic liquids have been investigated as a function of relative humidity.

\section{INSTRUMENT DESIGN}

\section{A. Overall description}

The EC includes a specimen chamber, a recirculating temperature-controlled water bath, a humidity generation system, and a proportional-integral-derivative (PID) control system. Table I shows the equipment specifications and brief descriptions. Temperature and relative humidity inside the specimen chamber are controlled primarily by mixing dry and saturated gas, wherein the saturated gas is generated by bubbling gas through temperature-controlled water reservoir. In addition, the temperature of the chamber walls is controlled by a double pass heat exchanger using water as the cooling and heating fluid.

The temperature and humidity inside the specimen chamber are recorded using an electric temperature/hydrometer from Rotronic ${ }^{\circledR}$ (Rotronic USA). The dry and saturated flows are controlled by two mass flow controllers from MKS Instruments. The temperature indicators, temperature-controllers, and flow meters are monitored and controlled via a custom Labview ${ }^{\circledR} 8.5$ program (National Instruments). The software incorporates a PID sequence to control the temperature and relative humidity inside the specimen chamber.

\section{B. Specimen chamber}

To study transient morphologies as a function of relative humidity or non-corrosive gases, we designed the specimen chamber to have a large escape angle to maximize the range of accessible scattering angles. In the horizontal direction the maximum escape angle is $2 \theta= \pm 30^{\circ}$, while it is even larger in the vertical direction. The specimen chamber prevents condensation inside the chamber and the compact size minimizes x-ray absorption. A novel attribute of our specimen chamber is the capability to mount multiple samples for increased throughput and for environmental conformity for all samples. The specimen chamber (Figure 1) includes the fol-

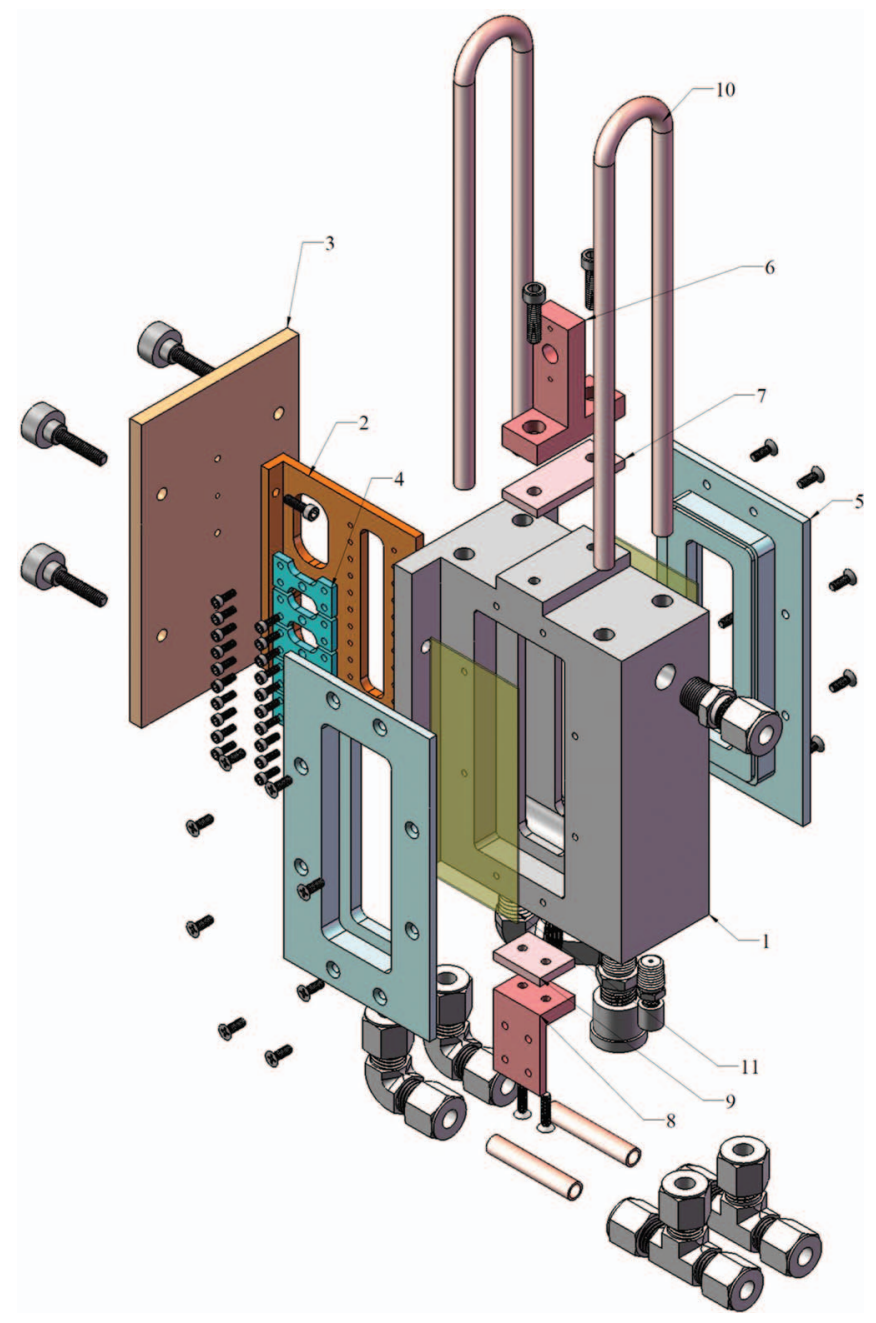

FIG. 1. (Color online) Specimen chamber 3D illustration. The specimen chamber includes the following components: (1) RH chamber, (2) sample mount, (3) door, (4) sample clamp, (5) window frames, (6) y-direction motor mount for vertical displacement, (7) insulator, (8) strain relief, (9) insulator for strain relief, (10) cooling loops, and (11) beryllium (Be) window. Key features of this new design include large escape angle (x-ray scattering angle $2 \theta= \pm 30^{\circ}$, horizontal), compatibility with an evacuated $\mathrm{x}$-ray chamber, capability to hold multiple samples, dynamic control of temperature and relative humidity, and computer control of temperature and relative humidity integrated with data collection.

lowing components: (1) RH chamber, (2) sample mount, (3) door, (4) sample clamp, (5) window frames, (6) y-direction motor mount for vertical displacement, (7) insulator, (8) strain relief, (9) insulator for strain relief, (10) cooling loops, and (11) beryllium $(\mathrm{Be})$ window. The outer dimensions are 4.5 in. $\times 1.5$ in. $\times 3.4$ in. and the inner dimensions are 3.55 in. $\times 0.75$ in. $\times 2.9$ in. The chamber is made from stainless steel 309. The sample mount is removable to facilitate sample changes. Each sample mount holds up to five individual samples $(\sim 0.50$ in. $\times 0.25$ in. $)$ using sample clamps (Figure 1). In essence, the sample mount allows the transmission of $\mathrm{x}$-rays and is connected to a removable door via four bolts.

To control the temperature and relative humidity of the sample environment, the specimen chamber has inlet and outlet connections to enable the flow of dry or moist 
temperature-controlled gas. The design of the specimen chamber allows good mixing and ample vapor exchange inside the specimen chamber. An internal electric temperature/hydrometer sensor probes the atmosphere within the sample chamber. This sensor measures from -40 to $100{ }^{\circ} \mathrm{C}$ with an accuracy of $\pm 0.1{ }^{\circ} \mathrm{C}$ and relative humidities from $0 \%$ to $100 \%$ with an accuracy of $\pm 1.5 \% \mathrm{RH}$. The sensor position can be changed in the y-direction within the sample chamber using a robust leak-tight connection. The removable door has a thermocouple located in the outer wall to record the temperature of the door and sample mount that serves as a secondary measure of the sample temperature in contact with the sample mount.

The specimen chamber includes two beryllium (Be) windows to minimize $x$-ray absorption. The Be windows (3.5 in. $\times 1.5$ in. $\times 0.025$ in.) provide a maximum horizontal exit angle of $\pm 30^{\circ}$ to allow a wide collection angle for the $x$-ray scattering experiments and to access the multiple sample positions. The x-ray path length between the Be windows is only 0.75 in. The Be windows are sealed to the chamber using a paste adhesive and further secured by window frames. The inner side of the Be windows is coated with a corrosion inhibitor due to the moist environment in the specimen chamber. The Be windows have a wall thickness of $0.025 \mathrm{in}$. $(635 \mu \mathrm{m})$. The thickness of the beryllium windows and the window frames provide a robust design to accommodate the pressure difference between the inside of the sample chamber $(1 \mathrm{~atm}=1013$ mbar) and the evacuated flight path chamber (0.1 mbar).

The walls of the specimen chamber include a double pass heat exchanger copper tube and a hole for a temperature sensor to measure the temperature of the chamber wall. The double pass heat exchanger controls the temperature of the specimen chamber walls using an external temperature-controlled water recirculation bath. The wall temperature is set 1 to $3^{\circ} \mathrm{C}$ warmer than the chamber atmosphere to prevent condensation on the walls and Be windows. The specimen chamber is connected to a linear motor mount, which controls the position in the y-direction (Figure 1). To prevent thermal loss due to conduction of heat to the motor mount, the specimen chamber is thermally isolated using an insulating spacer.

\section{Recirculating temperature-controlled water bath}

The wall temperature of the specimen chamber is controlled via a recirculation water bath using predetermined calibration curves. The walls of the specimen chamber incorporate copper tubing through which the water passes before returning to the temperature-controlled water bath. The 71 water recirculation bath temperature control range of -25 to $150{ }^{\circ} \mathrm{C}$ with a stability of $\pm 0.01{ }^{\circ} \mathrm{C}$. The water recirculation bath temperature is regulated using a PID controller, which is capable of cooling at $500 \mathrm{~W}$ and heating at $800 \mathrm{~W}$. The pressure pump has a maximum flow of $15 \mathrm{l} / \mathrm{min}$ at a maximum pressure of 5 psi. The inlet and outlet lines are connected to the specimen chamber through the wall of the evacuated flight path by two feed-throughs. The inlet and outlet lines inside the evacuated flight path are insulated to prevent heat losses to the environment.

\section{Humidity generator}

The temperature and relative humidity in the specimen chamber are controlled by flowing through the chamber warm, moist gas (typically nitrogen) from an external humidity generator. Saturated gas is generated when dry gas passes through a bottle filled with water at a designated temperature, the bottle temperature. The humidity generator includes the following: an immersion heater, two insulated Teflon bottles, a dry gas flow meter, a wet gas flow meter, a compressed gas line, a mixing line, and two heat traces.

The bottle incorporates two one-directional diffusers that prevent condensation and liquid water from entering the specimen chamber. The saturated gas flow is mixed with dry gas flow to achieve the desired relative humidity in the specimen chamber. The percent relative humidity (\%RH) is defined as the partial pressure of water vapor in the gas divided by the vapor pressure of water at a given temperature. Assuming that both the dry and saturated gases behave as ideal gases, the relative humidity can be expressed as

$$
\begin{aligned}
\mathrm{RH}(\%) & =\frac{p_{\mathrm{H}_{2} \mathrm{O}}}{p_{\mathrm{H}_{2} \mathrm{O}}^{*}} * 100=\frac{x_{\mathrm{H}_{2} \mathrm{O}}}{x_{\mathrm{H}_{2} \mathrm{O}}^{*}} * 100 \\
& =\frac{F_{1, \mathrm{H}_{2} \mathrm{O}}^{*}}{F_{1, \mathrm{H}_{2} \mathrm{O}}^{*}+F_{2}} \approx \frac{F_{1}}{F_{1}+F_{2}},
\end{aligned}
$$

where $p_{\mathrm{H}_{2} \mathrm{O}}$ is the desired partial pressure of water vapor, $p_{\mathrm{H}_{2} \mathrm{O}}^{*}$ is the saturated vapor pressure, $x_{\mathrm{H}_{2} \mathrm{O}}$ is the mole fraction of water, $x_{\mathrm{H}_{2} \mathrm{O}}^{*}$ is the saturated mole fraction of water, $F_{1, \mathrm{H}_{2} \mathrm{O}}^{*}$ is the flow rate of saturated gas escaping the bottle, $F_{1}$ is the flow rate of gas entering the bottle and $F_{2}$ is the flow rate of dry gas. The bottle incorporates a secondary water reservoir to minimize the loss of water inside the bottle. Since $F_{1, \mathrm{H}_{2} \mathrm{O}}^{*} \sim$ $F_{1}$, the relative humidity can be controlled by varying $F_{1}$ and $F_{2}$. The total flow to the specimen chamber is held constant at flow rate of $2000 \mathrm{cc} / \mathrm{min}$.

The inlet line carrying the humid gas is wrapped with a heat trace outside and inside the evacuated flight path to prevent condensation. There is no heat trace on the outlet line outside the evacuated flight path. The temperature of the heat trace is maintained at $20^{\circ} \mathrm{C}$ above the bottle temperature.

\section{E. PID controller}

The EC is controlled by a program written in LabVIEW 8.5 as outlined in the flow diagram, in Figure 2. The EC system has six independent variables that determine the temperature and humidity inside the specimen chamber. These variables are bottle temperature, outside heat trace temperature (HT1), inside heat trace temperature (HT2), $F_{1}, F_{2}$, and recirculating water bath temperature.

The program operates under two modes: manual and automatic. In manual mode, the user defines each of the six independent variables, and there is no PID function. In the automatic mode, the user sets the desired temperature and relative humidity; subsequently the six independent variables are calculated using predetermined calibration curves. Once each component has been set, the program will run a PID function to maintain $\% \mathrm{RH}$ at $\pm 1.5 \%$ relative to the set value. The 


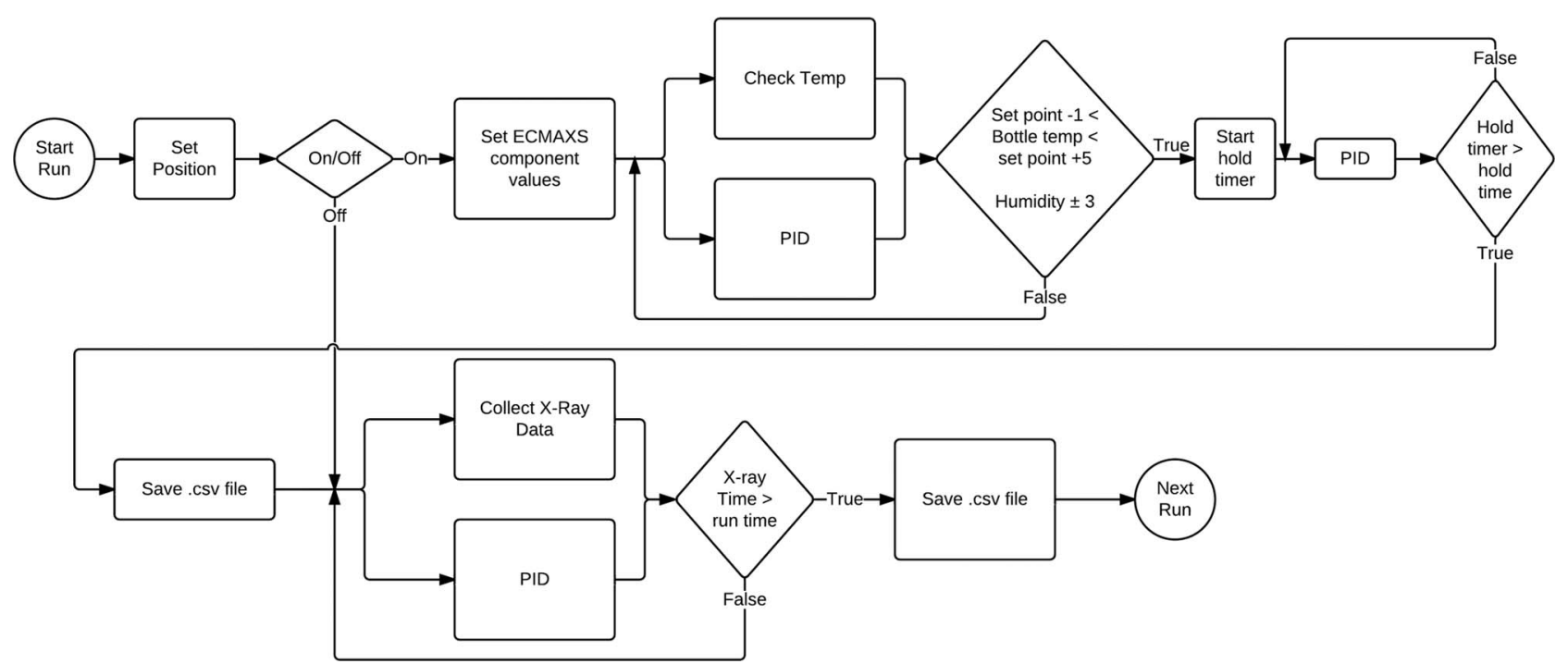

FIG. 2. Process control instrumentation flow diagram. Here, water recirculating bath temperature, bottle temperature, HT1 and HT2, and gas flow rates are the controlled variables. The system incorporates four continuous process controls and two manipulated variables. The control loop feedback mechanism regulates the saturation level of the gas by controlling the dry and saturated gas inlet flows using Eq. (1).

LabVIEW program also communicates directly with the PID controller from the humidity generator and the recirculating water bath system.

The control software is currently designed to collect $\mathrm{x}$-ray scattering data at static conditions of $\mathrm{T}$ and $\% \mathrm{RH}$. Naturally, modifications to the software could readily allow $\mathrm{x}$ ray scattering data to be collected while transitioning from one condition to another. To control the \% RH in the specimen chamber, the program uses feedback from changes in $\% \mathrm{RH}$ to alter saturated gas flow, $F_{1}$, and the dry gas flow, $F_{2}$, values. The PID function uses the ratio $F_{2}: F_{2} /\left(F_{1}+F_{2}\right)$ to regulate the desired condition. The equation is as follows:

$$
M V(t)=K_{p}\left(e(t)+\frac{1}{t_{i}} \int_{\max (0, t-500)}^{t} e(\tau) d \tau+t_{d} \frac{d}{d t} e(t)\right)
$$

where $M V(t)$ is the correction factor, $K_{p}$ is the proportional constant, $e(t)$ is the difference between measured and set point $\% \mathrm{RH}, t_{i}$ is the integral time, and $t_{d}$ is the derivative time. This is the traditional PID feedback control equation using parameters that were calibrated for this device. It is important to note, however, that Eq. (2) integrates in a transient mode over the last $500 \mathrm{~s}$ of data. This calculation is made every $5 \mathrm{~s}$, and the $F_{2}$ ratio is then corrected by $M V(t) . F_{1}$ and $F_{2}$ values are then set using the new $F_{2}$ ratio.

The first PID sequence runs until the bottle temperature in the humidity generator is 1 to $5^{\circ} \mathrm{C}$ below its set point. In addition, the humidity must be within 3\% RH of its set point. When these conditions are met, the first PID loop ends. Next, it copies the last $500 \mathrm{~s}$ of \% RH data to a second PID loop. The second PID sequence uses the same parameters as the first and runs for an amount of time that the user specifies. During this process, the program records the humidity and temperature values of the specimen chamber every $5 \mathrm{~s}$. Simultaneously, the program initiates the collection of $\mathrm{x}$-ray scattering data, for a designated period of time. Upon completion, the software goes to the next run.
Figure 3 shows the measured temperature and relative humidity as a function of time when the EC is set to $30^{\circ} \mathrm{C}$ with stepwise changes in relative humidity. The temperature as a function of time shows a temperature precision of $0.05^{\circ} \mathrm{C}$. At relative humidities from $0 \%$ to $95 \% \mathrm{RH}$ the EC exhibits excellent temperature control. The stepwise changes in the relative humidity show a response time of 1 to $2 \mathrm{~min}$
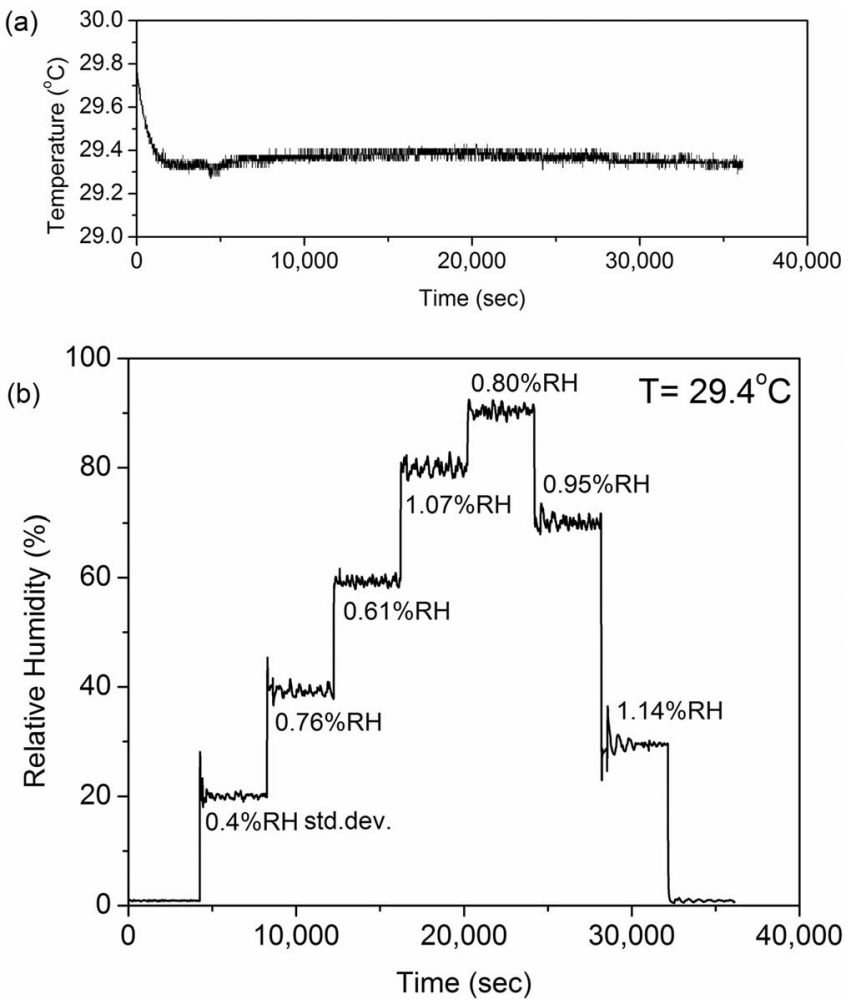

FIG. 3. Measured temperature (a) and relative humidity (b) for the EC when the temperature is set to $30^{\circ} \mathrm{C}$ and the relative humidity is changes stepwise. The measured temperature is controlled to a precision of $\pm 0.05^{\circ} \mathrm{C}$. The standard deviation of the \% RH is reported in part $\mathrm{b}$ and is $0.4-1.41 \% \mathrm{RH}$. 

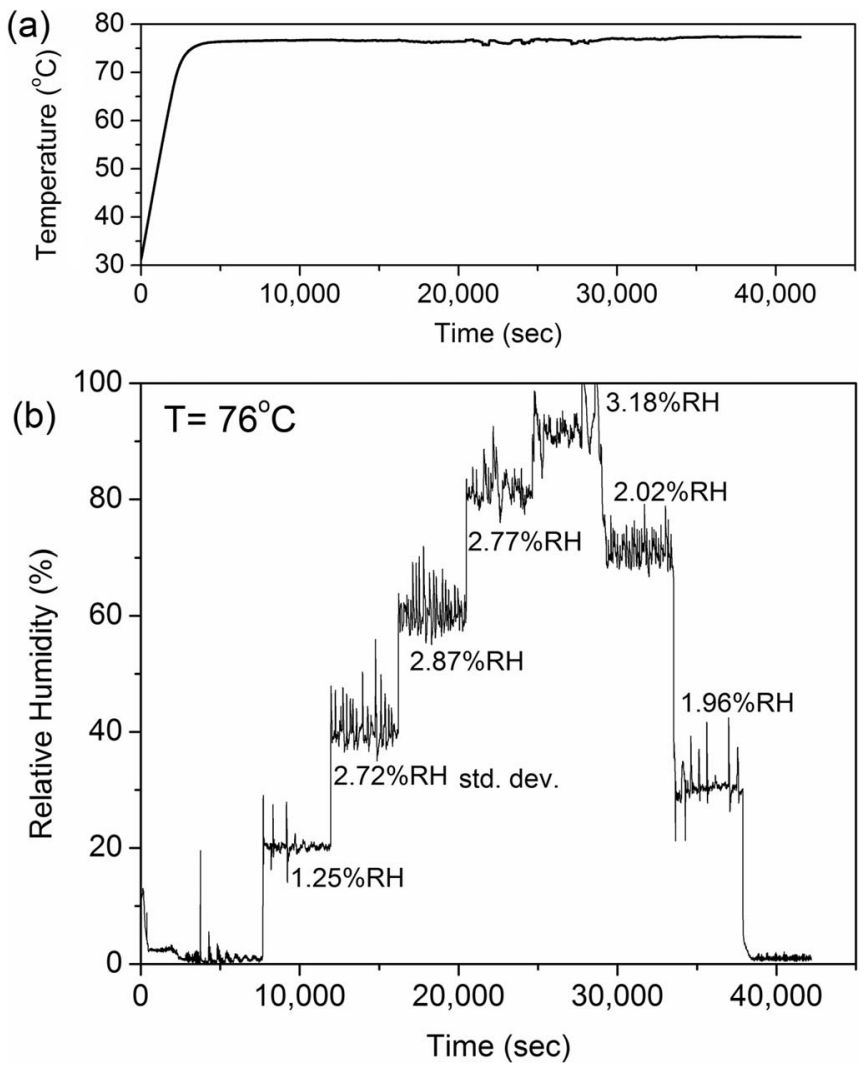

FIG. 4. Measured temperature (a) and relative humidity (b) for the EC when the temperature is set to $80^{\circ} \mathrm{C}$ and the relative humidity is changes stepwise. The measured temperature is controlled to a precision of $\pm 0.38^{\circ} \mathrm{C}$. The standard deviation of the \% RH is reported in part $b$ and is $1.25-3.18 \% \mathrm{RH}$.

without any significant overshoot. The relative humidity is maintained at $\pm 1.5 \% \mathrm{RH}$ of the set point. The fluctuation in the relative humidity with time is due to minor pressure fluctuations inside the specimen chamber as more saturated vapor enters and exits the system. These data demonstrate that our control system provides precise relative humidity and temperature control within the environmental chamber.

Figure 4 shows the measured temperature and relative humidity as a function of time when the set temperature is $80^{\circ} \mathrm{C}$. The temperature shows a variation from the set point of $4{ }^{\circ} \mathrm{C}$. However, the measured temperature shows precisions of $0.5^{\circ} \mathrm{C}$ as a function of time. The response time for changes in the RH is about 1 to $3 \mathrm{~min}$ and the overshoot is $50 \%$ of the set point at $20 \% \mathrm{RH}$ and $5 \%$ of the set point above $60 \% \mathrm{RH}$. The measured humidity shows a precision of up to $3 \% \mathrm{RH}$. The cell is less stable at higher temperature due to a reduced ability of the unit to efficiently removing the inlet gas stream with a higher mass rate of vapor. This causes pressure fluctuations inside the specimen chamber which result in changes in dew point. The stability of the specimen chamber could be increased by increasing the outlet orifice size which currently has a diameter of $1 / 4$ in.

\section{RESULTS AND DISCUSSION}

$\mathrm{X}$-ray scattering was performed with the multi-angle $\mathrm{x}$-ray scattering system (MAXS) at the University of

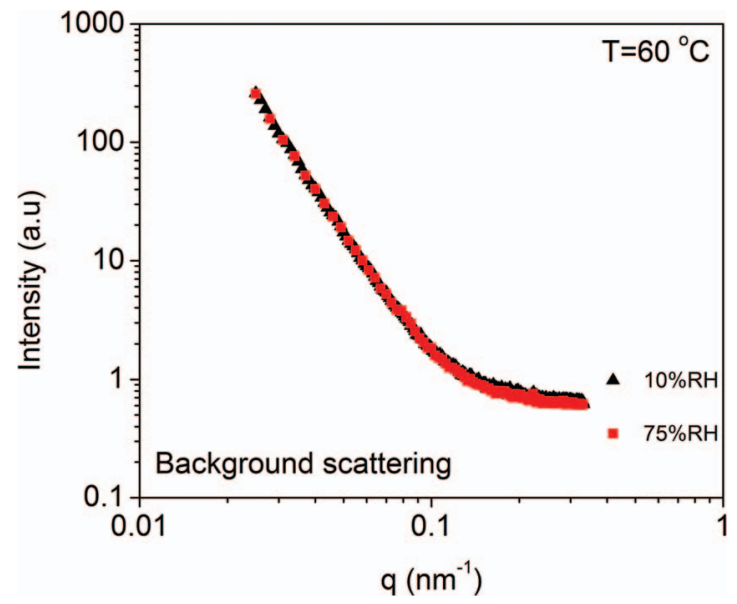

FIG. 5. (Color online) X-ray scattering through the environmental chamber without a sample as a function of relative humidity at $60^{\circ} \mathrm{C}$. Attenuation due to Be windows, nitrogen and water molecules is minimal.

Pennsylvania. The MAXS system generates $\mathrm{Cu}-\mathrm{K} \alpha$ x-rays, $\lambda=0.154 \mathrm{~nm}$, from a Nonius FR 591 rotating anode operated at $40 \mathrm{kV}$ and $85 \mathrm{~mA}$. The bright, highly collimated beam was obtained via Osmic Max-Flux optics and pinhole collimation in an integral vacuum system. The scattering data were collected using a Bruker Hi-Star two-dimensional (2D) detector with sample-to-detector distances of 11 and $54 \mathrm{~cm}$. As previously discussed the x-ray path length between the Be windows is 0.75 in., a distance that allows good vapor exchange near the samples while minimizing attenuation. The incident beam exhibits a 35\% reduction in intensity upon passing through the evacuated specimen chamber due to the two coated Be windows. The incident beam intensity remains constant at $60^{\circ} \mathrm{C}$ as a function of relative humidity from $10 \%$ to $75 \% \mathrm{RH}$, Figure 5. This result indicates that attenuation due to water vapor is minimal. Moreover, no new features appear as a function of relative humidity, which allows for easy subtraction. Note that the coating on the inside of the Be windows to prevent corrosion can exhibit Bragg scattering. As Figure 5 demonstrates, the scattering from the coated Be does not interfere with the $\mathrm{x}$-ray scattering measurements.

The capabilities and application of our in situ EC were tested on two polymers: Nafion ${ }^{\circledR}$ membranes and an imidazolium-based polymerized ionic liquid (PIL), Figure 6. The synthesis and characterization of these two polymer systems have been described elsewhere. ${ }^{20,21}$

Figure 7 shows the 2D scattering patterns (collected at $86 \% \mathrm{RH}, 25^{\circ} \mathrm{C}$ ) for the Nafion ${ }^{\circledR}$ cast film and electrospun Nafion ${ }^{\circledR}$ nanofiber. The data indicate that ionic aggregates are isotropic in the cast film and anisotropic in the nanofiber, which indicates the presence of oriented ionic domains along the fiber axis direction (Figure 7(b)). Figures 7(c) and 7(d) show the $\mathrm{x}$-ray scattering profiles as a function of relative humidity for $\mathrm{Nafion}^{\circledR}$ cast film and electrospun Nafion ${ }^{\circledR}$ nanofiber. The dry cast film and nanofiber have scattering maxima at $q \sim 1.77$ and $1.95 \mathrm{~nm}^{-1}$, respectively, indicating the presence of ionic aggregates. Upon exposure to relative humidity, the scattering maxima in both the cast film and nanofibers move to lower $q$, indicating the system is swelling 


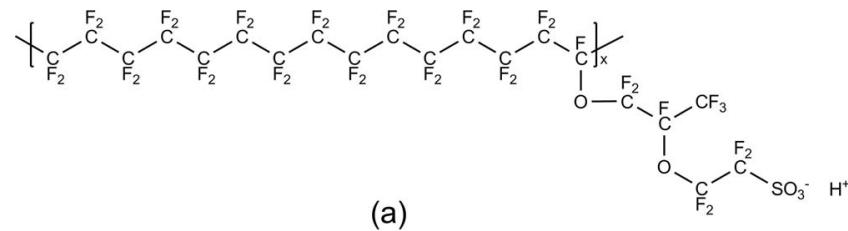

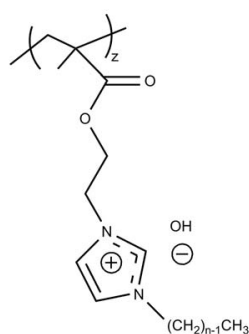

(b)

FIG. 6. Chemical structures for (a) Nafion ${ }^{\circledR}$ polymer and (b) poly(1[(2-methacryloyloxy)ethyl]-3-butlyimidazolium-hydroxide) (poly(MEBIM$\mathrm{OH})$.

on the nanometer scale. Similar results have been reported elsewhere for cast Nafion ${ }^{\circledR}$ membranes using small-angle $\mathrm{x}$ ray scattering or small-angle neutron scattering as a function of relative humidity. ${ }^{4,14,16}$ For example, Kim et al. ${ }^{4}$ demonstrated that the shift to lower $q$ of the inter-aggregate scattering peak of Nafion ${ }^{\circledR}$ polymer with increasing relative humidity is due to expansion of the distance between ionic domains. The Nafion ${ }^{\circledR}$ nanofiber has a shift in $q$ with increasing relative humidity due to an increase in distance between the aligned nano-domains. ${ }^{20}$

Figure 8 shows the $\mathrm{x}$-ray scattering as a function of relative humidity for poly(MEBIM-OH). The scattering peaks are designated as follows: $q_{\mathrm{I}}=4.25 \mathrm{~nm}^{-1}, q_{\mathrm{II}}=6.14 \mathrm{~nm}^{-1}$, and $q_{\mathrm{III}}=15.15 \mathrm{~nm}^{-1}$ (amorphous halo). As the relative humidity increases, the scattering peaks $q_{\mathrm{I}}$ and $q_{\mathrm{II}}$ evolve into one scattering peak located at $4.95 \mathrm{~nm}^{-1}$, while $q_{\mathrm{III}}$ moves to a higher angle. We suspect that at $80 \% \mathrm{RH}$, the low- $q$ scat- (a)
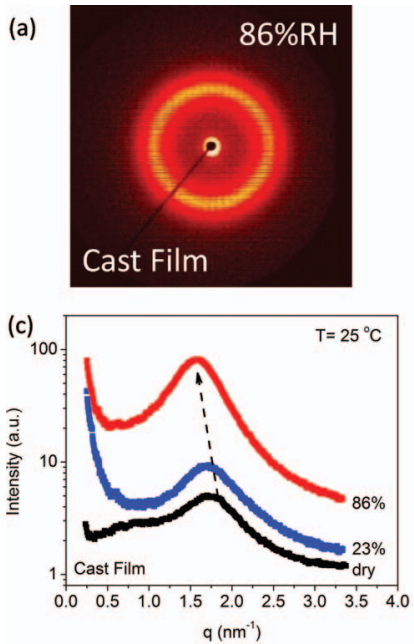

(b)

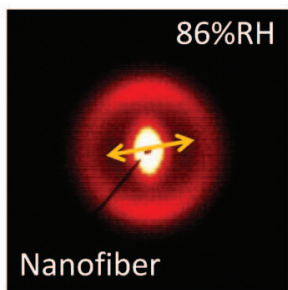

(d)

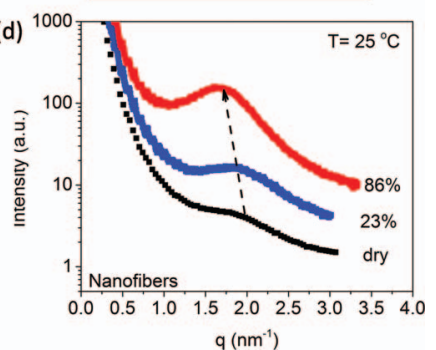

FIG. 7. (Color online) $2 \mathrm{D}$ x-ray scattering pattern (at $86 \% \mathrm{RH}, 25^{\circ} \mathrm{C}$ ) of (a) Nafion ${ }^{\circledR}$ cast film and (b) Nafion ${ }^{\circledR}$ nanofiber (arrow indicating longitude direction of fibers).$^{20} \mathrm{X}$-ray scattering profile as a function of relative humidity for (c) Nafion ${ }^{\circledR}$ cast film and (d) Nafion ${ }^{\circledR}$ nanofibers. The x-ray scattering data are shifted vertically for clarity.

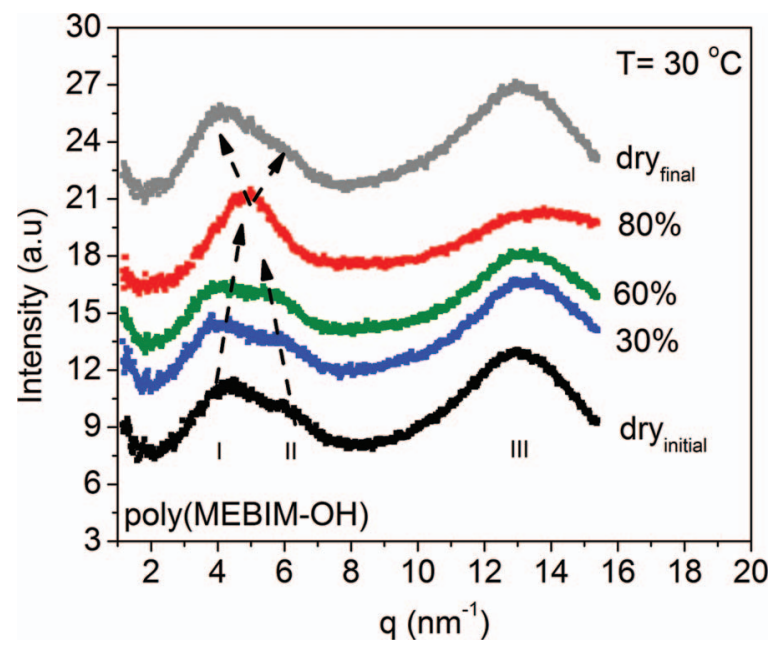

FIG. 8. (Color online) X-ray scattering profile as a function of relative humidity for a polymerized ionic liquid. The X-ray scattering profiles are shifted vertically for clarity.

tering peak results from the combination of two backboneto-backbone correlation lengths arising from different anions $\left(\mathrm{OH}^{-}, \mathrm{HCO}_{3}{ }^{-}\right.$, and $\left.\mathrm{CO}_{3}{ }^{-2}\right)$ in the poly(MEBIM-OH) polymer. Fukuta et al. ${ }^{22}$ reported that $\mathrm{CO}_{2}$ absorbs to alkaline membranes, that is, $\mathrm{OH}^{-}$degrades in $\mathrm{CO}_{2}$ to produce $\mathrm{HCO}_{3}{ }^{-}$ and $\mathrm{CO}_{3}{ }^{-2}$. Garand et al. $^{23}$ showed evidence to suggest that water molecules bind to the negatively charged $\mathrm{CO}_{2}$ moieties of the $\mathrm{HCO}_{3}{ }^{-}$playing a central role in the acid-based equilibrium formed when $\mathrm{CO}_{2}$ is dissolved in water. Further analysis and discussion is provided elsewhere. ${ }^{21}$ Upon reducing the relative humidity to less than $1 \%$ in the EC, the new scattering maximum reverted back to two scattering peaks, indicating that the morphology is fully reversible. Overall, these two polymer systems demonstrate the importance of collecting $\mathrm{x}$-ray scattering as a function of relative humidity. The new morphological information will advance the understanding of the fundamental relationship between morphology and other properties such as ionic conductivity and will enable the design of enhanced materials.

\section{CONCLUSION}

We have reported the design and characterization of an in situ environmental chamber for transmission $\mathrm{x}$-ray scattering experiments. Key features include large escape angles, the capability to mount multiple samples, dynamic control of temperature and relative humidity, and integrated computer control. The specimen chamber is compatible with a completely evacuated system such as the Rigaku PSAXS system, in which the specimen chamber is placed inside a larger evacuated chamber (flight path). It is also compatible with $\mathrm{x}$ ray systems consisting of flight tubes interspersed with small air gaps near the sample. Minor modification would adapt the chamber for synchrotron X-ray sources and in situ neutron scattering. This environmental chamber can be utilized to study transient morphologies as a function of temperature, relative humidity, and exposure to non-corrosive gases.

We have demonstrated the efficacy and reproducibility of the system to control temperature and relative humidity. 
At $30^{\circ} \mathrm{C}$, the temperature shows a deviation of $0.6^{\circ} \mathrm{C}$ from the set point and temperature precision of $\pm 0.05^{\circ} \mathrm{C}$ at relative humidities from $0 \%$ to $95 \% \mathrm{RH}$. The relative humidity shows a response time between 1 and 2 min with minimal overshoot and a precision of $\pm 1.5 \% \mathrm{RH}$. At $80^{\circ} \mathrm{C}$, the temperature shows a deviation of $4{ }^{\circ} \mathrm{C}$ and a temperature precision of $\pm 0.5^{\circ} \mathrm{C}$. The relative humidity shows precisions of $\pm 3 \%$ $\mathrm{RH}$. The response time for changes in the $\mathrm{RH}$ is $\sim 1$ to $3 \mathrm{~min}$ and the overshoot is $5 \%$ of the set point above $60 \% \mathrm{RH}$. The incident beam intensity remains constant as a function of relative humidity indicating that attenuation due to nitrogen and water vapor is minimal due to the short beam path within the EC. Additionally, we demonstrated its potential by studying the morphologies of Nafion ${ }^{\circledR}$ membranes and a polymerized ionic liquid as a function of relative humidity. This environmental chamber extends the possibilities for a detailed understanding of the transformation of morphology of materials.

\section{ACKNOWLEDGMENTS}

We thank Professor Yossef A. Elabd, Dr. Bing Dong, and Dr. Yuesheng Ye for providing the Nafion ${ }^{\circledR}$ nanofibers and imidazolium-based polymerized ionic liquids. Also, we thank Thomas B. Schmiedel and Chris W. Gray from W. L. Gore and Associates Inc. for technical advice and assistance. Funding for the construction of this device was provided by the Laboratory for Research on the Structure of Matter (NSFMRSEC-05-20020). D. Salas-de la Cruz was supported by the Ionic Liquids in Electro Active Devices (ILEAD) MURI grant (CR-19314-430286).

${ }^{1}$ D. T. Hallinan and Y. A. Elabd, J. Phys. Chem. B 113, 4257 (2009).

${ }^{2}$ M. J. Park, K. H. Downing, A. Jackson, E. D. Gomez, A. M. Minor, D. Cookson, A. Z. Weber, and N. P. Balsara, Nano Lett. 7, 3547 (2007).
${ }^{3}$ S. Xhang, K. Lee, C. D. Frisbie, and T. P. Lodge, Macromolecules 44, 940 (2011).

${ }^{4}$ M.-H. Kim, C. J. Glinka, and S. A. Grot, et al., Macromolecules 39, 4775 (2006).

${ }^{5}$ J. R. Varcoe, Phys. Chem. Chem. Phys. 9, 1479 (2007).

${ }^{6}$ S. A. Wilson, R. P. J. Jourdain, Q. Zhang, R. A. Dorey, C. R. Bowen, M. Willander, Q. U. Wahab, M. A. H. Safaa, O. Nur, E. Quandt, C. Johansson, E. Pagounis, M. Kohl, J. Matovic, B. Samel, W. van der Wijngaart, E. W. H. Jager, D. Carlsson, Z. Djinovic, M. Wegener, C. Moldovan, R. Iosub, E. Abad, M. Wendlandt, C. Rusu, and K. Persson, Mater. Sci. Eng. R. 56, 1 (2007).

${ }^{7}$ M. Guvendiren, S. Yang, and J. A. Burdick, Adv. Funct. Mater. 19, 3038 (2009).

${ }^{8}$ S. K. Singh, S. P. Tambe, V. S. Raja, and D. Kumar, Prog. Org. Coat. 60, 186 (2007).

${ }^{9}$ F. Liu, C. S. Roper, J. R. Chu, C. Carraro, and R. Maboudian, Sens. Actuators, A 166, 201 (2011).

${ }^{10}$ D. A. Constantinou, J. L. G. Fierro, and A. M. Efstathiou, Appl. Catal., B 95, 255 (2010).

${ }^{11}$ M. C. C. Ferrer, S. Yang, D. M. Eckmann, and R. J. Composto, Langmuir 26, 14126 (2010).

${ }^{12}$ Q. X. Wu and T. S. Zhao, Int. J. Hydrogen Energy 36, 5644 (2011).

${ }^{13}$ G. S. Smith, E. B. Sirota, C. R. Safinya, R. J. Plano, and N. A. Clark, J. Chem. Phys. 92, 4519 (1990).

${ }^{14}$ J. Halim and G. G. Scherer,Macromol. Chem. Phys. 195, 3783 (1994).

${ }^{15}$ J. Bang, B. J. Kim, G. E. Stein, T. P. Russell, X. Li, J. Wang, E. J. Kramer, and C. J. Hawker, Macromolecules 40, 7019 (2007).

${ }^{16}$ M.-H. Kim, C. J. Glinka, and R. N. Carter, Rev. Sci. Instrum. 76, 113904 (2005).

${ }^{17}$ E. B. Sirota, G. S. Smith, C. R. Safinya, R. J. Plano, and N. A. Clark, Science 242, 1406 (1988)

${ }^{18}$ J. Katsaras and M. J. Watson, Rev. Sci. Instrum. 71, 1737 (2000).

${ }^{19}$ A. Giahi, M. E. A. Faris, P. Bassereau, and T. Salditt, Eur. Phys. J. E 23, 431 (2007).

${ }^{20}$ B. Dong, L. Gwee, D. Salas-de la Cruz, K. I. Winey, and Y. A. Elabd, Nano Lett. 10, 3785 (2010).

${ }^{21}$ D. Salas-de la Cruz, Morphology and Ionic Conductivity of Polymerized Ionic Liquids. Ph.D. dissertation (University of Pennsylvania, 2011).

${ }^{22}$ K. Fukuta, H. Inoue, S. Watanabe, and H. Yanagi, ECS Trans. 19, 23 (2009).

${ }^{23}$ E. Garand, T. Wende, D. J. Goebbert, R. Bergmann, G. Meijer, D. M. Neumark, and K. R. Asmis, J. Am. Chem. Soc. 132, 849 (2010). 